\title{
Factors of Actualization of the Resource of Social and Political Participation of Youth
}

\author{
Natalia V. Kamenez
}

\begin{abstract}
The continuity of social, political, economic, sociocultural transformations is becoming a hallmark of modern society. The high speed of the changes and the crises with which they are associated create the risk of individual and group social maladaptation. In this article, the authors consider features that analyze and systematize the factors of actualizing the resource of political participation of youth, the criteria for systematizing factors: the external and internal environment, fixed, situational. They are not only interconnected, but also interdependent. Factors related to external ones influence the formation of internal ones (in a stable, economically developed society, in which the basic material needs of people are satisfied, the first place is satisfaction of social and prestigious needs, and especially in political participation); with a certain set of internal factors, situational factors are formed (in the absence of political interest in a young person, even the most professionally prepared propaganda and motivational technologies will not give the desired effect).
\end{abstract}

Keywords : youth, system of factors, political participation, political involvement, political system, socialization.

\section{INTRODUCTION}

The continuity of social, political, economic, sociocultural transformations is becoming a hallmark of modern society. The high speed of the changes and the crises with which they are associated create the risk of individual and group social maladaptation. Masses of people are becoming outsiders. This risk especially increases in societies undergoing a modernization process.

The specific position of young people in society, the relatively small amount of their social capital increase the risk of social outsider and deprivation [1].

The effect of the factor of social outsider is also manifested in the sphere of political culture. In general, the political culture of Russian youth is characterized by a gap between normative-value and behavioral levels, a low level of real civic activism, a weak interest in and distancing from politics, the dominance of instrumental values, a low level of trust in most political institutions, and the legitimization of violence. Thus, according to a number of surveys, the declared interest of young people in politics is slightly lower than that of other age groups [2].

Based on the above concepts, it is possible to interpret political activity as a set of actions of individuals aimed at changing or improving the socio-economic order, achieving certain socio-political, national and ideological goals.

Revised Manuscript Received on September 22, 2019.

* Correspondence Author

Natalia V. Kamenez, Tyumen Industrial University, Russia
In the context of political science, we can conclude that activity is the psychological and political self-movement of a citizen, excited by the actions of the authorities. In accordance with this distinguish:

- positive or negative reactions of people to impulses emanating from the political system of society, from its representatives and institutions, not related to the need for high activity;

- activity associated with the delegation of political authority, that is, the electoral behavior of people;

- participation in the activities of various political and public organizations;

- the performance of political functions within the institutions that are part of the political system of society or acting against it;

- direct activity within or outside political movements, directed against the existing political system and having as its main goal its radical restructuring [4].

\section{METHODOLOGY}

This article analyzes literature containing a study of the reasons for the activation of the political potential of youth. A comprehensive analysis of theories and practical research allows us to create a full-fledged, systematic view of the influence of various factors on the political participation of the young population. This analysis will help public and political actors interested in increasing the participation of youth in the political sphere to identify and systematize technologies that can stimulate and regulate the political involvement of youth. The method of system-structural analysis of the main modern terms and concepts allows you to more accurately understand their applicability in the study. Using the method of systematizing the results, it became possible to summarize the results of the study and draw the appropriate conclusions. The synergistic approach in this study contributed to the consideration of factors that could increase youth interest in political life.

The article is aimed at studying the factors affecting the involvement of young people in political life, and their actualization, as well as the formation of a comprehensive presentation on this issue.

\section{RESULTS}

Studying the political participation of citizens and youth, domestic and foreign researchers not only gave an interpretation of the concept, pointed out the versatility of its application, but also highlighted the essential (ideological and social aspects, legality, efficiency) and formal aspects of the phenomenon (forms, factors,

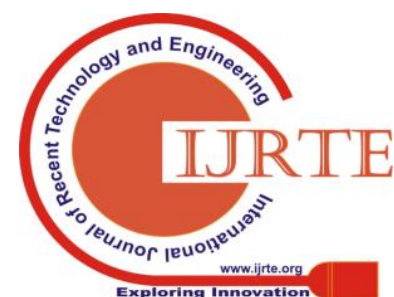


levels, methods, structures, criteria, national differences).

Young people, possessing great adaptive abilities, social mobility, more quickly and reliably master innovative technologies and new professions in the conditions of a post-industrial society. This group is most susceptible to the new socio-political system, to the values of a democratic society. It becomes obvious that the result and effectiveness of further transformations largely depends on the degree of inclusion of the young generation in the socio-political life of the country. The political participation of youth is one of the components of the process of structuring civil society and determines the prospects for its functioning, rather than declaration.

Youth as a special socio-demographic group is the most dynamic part of society and is characterized by a specific role and place in the system of social relations. Youth is a large open, age group, necessary for the normal functioning of society; therefore, youth problems are problems of the whole society.

One of the first definitions of the concept of "youth" in Russian sociology was given in 1968 by V.T. Lisovsky: "Youth is a generation of people who go through the stage of socialization, assimilate, and, at a more advanced age, already assimilated, educational, professional, cultural and others social functions "[5]. A more detailed definition was given by I. S. Kon: "youth is a socio-demographic group, distinguished on the basis of a combination of age characteristics, characteristics of social status and socio-psychological properties caused by both." He further clarifies the concept of "youth" as a certain phase, a stage in the life cycle of a biologically universal one, depending on the social system, culture and the laws of socialization that are characteristic of a given society [6].

The young generation performs special social functions in society and has its own characteristics:

youth inherits the level of development of society and the state and bears the function of social reproduction;

young people have their own goals and interests, which do not always coincide with the goals of the whole society;

young people are distinguished by insufficient life experience, which increases the likelihood of an erroneous choice when making responsible decisions, etc.

The system of relations "society - youth" is a dialectical interaction of the whole and part: society forms the appropriate type of youth, while the latter largely determines the development trend of society, its future. The public interest in youth issues means creating conditions for the development of the potential of a young person (his intellect, spirituality, education, national mentality, patriotism, etc.), as well as conducting a thoughtful humanistic (philanthropic) youth policy.

In the transitional state of modern society (from industrial to postindustrial), the role of a free active creative person, capable of making independent decisions, assimilation of progressive ideas, values, educational and social technologies, is growing. In this regard, the problems of understanding the political socialization of youth in the changing conditions of a transitional society are of particular relevance. The modern model of life, based on the consumer attitude to nature, the absolutization of commercial success, the achievements of mass culture, the tendency of narrow specialization of education, etc., does not meet the modern requirements of society and its development trends. The need for a critical analysis of social development guidelines, as well as the transition to a morally reflective model of human life, based on such concepts as: self-esteem, self-affirmation, responsibility, self-actualization, self-report, forecasting performance, etc., becomes more and more obvious.

One of the conditions for the development of society is the vitality of youth in the present and in the future. The development of society as a whole depends on what the position of the young generation is, its appearance, worldview, health, and disposition towards a productive existence. Consideration of the aforementioned problems will make it possible to optimize the models of youth socialization in the conditions of democratic renewal of society as a full and full-fledged subject.

The interest of modern science in the problems of youth socialization is explained by the fact that youth is a "social group necessary for the normal functioning" [6]. The young generation, being included in the system of social relations, is called upon, on the one hand, to assimilate, reproduce the material living conditions and experience gained by previous generations, and on the other, to accumulate the potential for its transformation and renewal. In this sense, the process of political socialization of youth as a factor in the development of the entire political system seems relevant. Political socialization, being a component of the political system, includes the process of including an individual in the socio-political environment, introducing him to the norms of political culture and reproducing the system of political relations, processes and phenomena through active political activity.

The age boundaries of this group are mobile and slightly different from the point of view of the anthropological, psychological and social approach. However, in general, we can say that this group includes people aged 14 to 30 years. Structurally, it is customary to divide it into several subgroups, since youth age is quite long and there are physiological, psychological and social differences depending on whether young people belong to the youth period or to older age subgroups of youth age.

In social terms, it is with young people that the prospects for the development of any society are associated, therefore, the process of their growing up and socialization is the subject of attention of both state structures and various social institutions.

Modern researchers highlight the factors affecting citizen participation in the political process: the individual psychological characteristics of a person and social conditions that are reflected in the political and cultural life of society. The most important factors determining the political behavior of youth in modern Russia, the researchers include: political and economic instability, mass poverty, sharp social stratification, weak power and the protracted search for a way out of their crisis.

Youth is the most mobile and dynamic layer of society, but the demographic perspective for the country at the moment, as recognized by both the government and society, is not particularly optimistic.

When analyzing the factors determining political 
participation, many theories suggest that the political participation of citizens causes changes in variables in the socio-economic and political spheres and affects the psychological characteristics of the individual [3].

Nevertheless, there are a sufficient number of factors that require analysis and systematization, which to one degree or another affect the political participation of youth (level of education, standard of living, level of trust in political institutions, forms and methods of communication between political institutions and young people, etc. .).

When considering the factors of updating and blocking the motives of personal

Directly "actualization" - is translated as "implementation; transition from a state of opportunity to a state of reality. " In German, the term "reality" as a translation of the Latin word "actualitas" ("effectiveness") was introduced by Meister Eckhart. The German concept of "effectiveness" contains an important component of action, while in ancient Greek and Latin, reality is identical with truth. In French and English - with reality. In neotomism, the concepts of "reality" and "opportunity" are used along with the concepts of "act" and "potency." Based on the analysis of the meaning of the word "actualization", the psychological phenomenon of actualization seems to us to be a transition of some property or phenomenon from possible to real.

In our opinion, it is logical to single out the following criteria for systematizing factors: the first pair of criteria is the external environment (processes that change not only vital activity, but also the social life of the individual) and internal (processes that are formed on the basis of the personality characteristics of the individual and his perception) in relation to the subject of political participation (young person); the second pair is fixed (formed over the entire conscious life of a person, has a long-term impact both before and after political participation) and situational circumstances (formed quickly, has a short-term impact, usually aimed at specific political participation here and now).

As a result, at the intersection of the criteria, 4 groups of factors are formed.

The group of internal fixed factors includes factors that influence the political behavior of a young person on an ongoing basis, relying on and shaping his internal environment and personality characteristics. Factors that are formed during the electoral age of a young person have a long-term impact both before and after political participation. The main ones in this group are socialization, motivation, and educational level.

Almost all researchers recognize that the key factors affecting political participation begin to take effect in childhood. In particular, the first stages of socialization form basic characteristics, such as the socio-economic status of parents, gender, experience gained (social activity at school). Speaking about internal fixed factors affecting political participation, we should first highlight socialization, which includes not only conscious, controlled, deliberate influences, but also spontaneous, spontaneous processes that are somehow involved in the formation of personality. However, these influences form precisely the inner attitude of the young man, including politics. Researchers distinguish two phases of socialization: social adaptation (adaptation of an individual to socio-economic conditions, role functions, social norms, the environment of his life) and interiorization (the process of incorporating social norms and values into the human inner world) [7, p. 141]. It is internalization that plays an important role in the formation of interest and knowledge of a young man about politics, and allows the formation of conditions for political participation (non-participation) through socio-political channels.

Consider a factor such as motivation, through the prism of the classical theory of needs A. Maslow. If we shift the basic needs to the political sphere, we can assume that it is the consistent satisfaction of certain needs that will motivate people to political participation, for example: living standards (physiological needs), social stability (need for security), membership in political organizations (social needs ), status and prestige (self-affirmation), expression and realization of political interests and beliefs (self-actualization). In addition, the studies of D. Maclelland and J. Atkins [8] showed that the main motives that determine political participation include the motive for possessing power (the motive for control); motive of achievement (goals, success); motive to avoid negative developments; the motive of affiliation (establishing warm, friendly relations with others).

An important role in this group is played by political education. Education provides citizens with the skills and resources necessary to participate in political life. For example, S. Verba argues that education not only directly increases the level of political participation, but also allows citizens to acquire the civic skills necessary for effective interaction with politicians [9]. According to S. Rosenstone and D. Hansen, education "conveys knowledge and skills that are essential for a citizen's tasks ... a well-educated person has the skills that people need to understand a political subject, participate in a political campaign, and study and evaluate problems and candidates "[7, p. 136]. From their point of view, the process of formal education leads to an increase in political participation. However, there are many more mechanisms to consider. We use the term "educational" to mean those factors that take a long time to form, but are expected to have a longer effect. These are socio-political skills, experience, trust, social capital and citizenship.

The group of external fixed factors includes those that form a constant environment in which a young person exists and develops. These factors are formed regardless of a particular person and have a long-term effect. The main ones in this group are: the political system, socio-economic indicators, civil society, social capital.

The main factor in this group, we consider the political system, which includes the institutional (regime, form of government and form of territorial structure; the presence in the country of elected institutions of power; the presence of political parties and features of the party landscape; type of electoral system, etc.), communicative (relations and relations between subjects and objects of the political system), normative (the existence of political and legal norms governing the process of exercising political power) and ideological components (pre most likely political culture). 
Factors of the economic and socio-demographic sphere influence the degree and forms of political activity. S. Verba and N. Nye considered the socio-demographic characteristics of the population as basic factors of political participation and activity [8, p. 46]. Citizens with higher incomes are more clearly aware of the influence of politics on their lives and have the necessary resources (time, knowledge) to influence government decisions through voting and other forms of conventional participation. S. Lipset and D. Lerner, proving the interdependence of socio-economic development and forms of participation, came to the conclusion that there are two models of interconnection - liberal (economic stability reduces social inequality, leads to conventional forms of participation and political stability) and populist (un-institutionalized participation aimed at redistributing benefits entails the destabilization of the political system) [4, p. 16].

In the same group, it is worth noting the level of development of civil society: the availability of opportunities to participate in unions, religious groups, socially oriented groups (voluntary and human rights) and the presence of institutional forms of social interaction make it possible to directly, legally carry out social and political participation.

Social capital, being a group resource, is created by a free and rational individual to achieve his own benefits. In other words, a society with significant social capital is able to provide citizens with the opportunity to achieve political goals, access to information, and social support. The question is only in relation to the individual, his desire to use the proposed resources. R. D. Putnam, for example, argued that social capital influences the level of participation in various types of socio-political organizations and associations [10]. Therefore, it is natural that people with significant financial or human capital are more likely to participate; people who are members of social networks that contain other members are more likely to participate because they will be asked to participate.

The group of internal situational factors includes factors that have a short-term and, as a rule, one-time effect on political participation, based on the situation's self-interest and self-interest of the young man. They are formed unplanned, quickly and just as quickly disappear. The main factor in this group is the rational choice.

A young man who has a certain fixed set of knowledge and skills, when making decisions, including political ones, is guided by internal conclusions. The theory of rational choice, which came from economic theory, serves as one of the foundations for the formation of a factor determining political participation. It is based on the idea that any socio-political activity is carried out rationally, and before doing something, the person calculates the likely costs and benefits of any action. Therefore, we can assume that in order to understand the forms of political participation, it is enough to know the interests of factors and assume that they will rationally implement them.

This group also includes various psychological components of political participation, such as instincts, which are formed at the very beginning of a person's life.

The group of external situational factors includes factors that are created by entities interested in motivating (demotivating) young people to political participation. They are formed in a short time, as planned, have a short-term impact on the decision to participate in the political process. The main groups in this group are mobilization and recruitment (recruiting) networks, the pressure of others, the flow of political information, administrative resources, and social and political events.

Factors that fall into this group can have a direct impact on political participation (for example, young people are urged (persuaded) to vote for a particular candidate) or work through increased political interest (for example, the flow of political information makes some people more interested in politics and, therefore more likely to vote). It should also be noted that there are lottery drawings for young voters on election day, the use of administrative resources to increase the attendance of employees of state institutions, and various thematic contests for children.

In addition, we note that situational factors, in particular a change in the flow of political information, can change a person's political interests, attitudes, or attitudes in ways that potentially affect political participation.

It should be borne in mind that the division into fixed, situational, educational and personal factors is rather arbitrary. They are not only interconnected, but also interdependent. Factors related to external ones influence the formation of internal ones (in a stable, economically developed society, in which the basic material needs of people are satisfied, the first place is satisfaction of social and prestigious needs, and especially in political participation); with a certain set of internal factors, situational factors are formed (in the absence of political interest in a young person, even the most professionally prepared campaigning and motivational technologies will not give the desired effect), etc.

\section{CONCLUSION}

The political participation of youth in socio-political processes is today a fundamentally important factor, since it reveals a clear dependence of conscious political behavior on socio-political technologies and the level of attention to government political movements by public authorities. It is an objective characteristic that gives an idea of the sources, specificity, contradictions in the methods of action (or refusal of any actions) in the existing modernization processes in Russia. The behavioral approach to the study of political participation gives the most accurate picture of the strategy and types of actions chosen by the subject and object of politics. It is necessary to pay attention to the fact that "power adaptation", on the one hand, carries, according to E. Meleshkina, "the strongest element of uncertainty", with the consequence of the inconsistency and unpredictability of adaptation strategies, on the other.

The youth political movement represents a kind of resource for state and political authorities, allowing it to exercise its own interest in the environment of material values (economic); in the field of creation and implementation of various benefits and privileges (social); in the sphere of influence on the inner world of a person, directly or indirectly forcing him to change the motivation of activity (informational, spiritual, moral, mental, 
religious). As analysis has shown, in Russia since ancient times the young generation has been involved in social and political relations at the state level, starting from Kievan Rus, when, in the opinion of V.I. Kovlenko and A.N. Medushevsky, begins the history of the political life of the Russian people, accompanied by the formation of Russian political and legal thinking. Using participation as an inherent property of any managed (or self-governing) community, it was possible to solve both objective (behavioral) and subjective (psychological) problems of youth adaptation to political processes and at the same time predetermine their political status.

Based on the analysis of motivational terminology, it should be noted that the actualization of the motives for participation in the activity is the result of the transition from the state of possibility to the state of reality of the elements of the content and dynamic aspects of personal motivation.

In aggregate, the factors systematized according to the criteria proposed in this article determine the formation of motivation (interest) in participating in the political process, knowledge of its features and the effectiveness of its actors, and therefore increase the political involvement of young citizens in the political process.

\section{REFERENCES}

1. Reutov EV Political mobilization of youth as a technology to minimize social outsider / Belgorod region: past, present. The future: materials regional. scientific and practical conf. Belgorod, 2016.S. 110-117.

2. Interest in politics: monitoring // Publishing mode: http://bd.fom.ru/report/map/proiects/dominant/dom0625/domt0625 $1 /$ tb062507. - System requirements: IBM PC; Internet Explorer

3. Ryabukhina Yu.N. The system of factors of youth political participation // South Russian Journal of Social Sciences. 2012. No3. URL: https://cyberleninka.ru/article/n/sistema-faktorov-politicheskogo-uchasti ya-molodyozhi (accessed: 01.10.2019).

4. Gayfullin A.Yu., Rybalko N.V. Diagnostics of the development of political activity of youth // VEGU Bulletin. 2011. No 6 (56)

5. Sociology of Youth: Textbook / Ed. prof. V.T. Lisovsky. - St. Petersburg: Publishing House of St. Petersburg University, 1996. 460 p.

6. 6. Kon I.S. Sociology of youth. In the book: A Brief Dictionary of Sociology M., 1988.

7. Belikova E. A. Political participation of youth: analysis of the problems of political activity / E. A. Belikova // Central Russian Bulletin of Social Sciences. 2014. No1 (31). URL: https://cyberleninka.ru/article/n/politicheskoe-uchastie-molodezhi-analiz -problem-politicheskoy-aktivnosti (accessed September 29, 2019)

8. Kopaeva E. V., Kotova K. A., Lisova S. Yu. Political activity of students: problems and trends / E. V. Kopaeva, K. A. Kotova, S. Yu. Lisova // Manuscript. 2017. No. 6-1 (80). URL: https://cyberleninka.ru/article/n/politicheskaya-aktivnost-studencheskoy -molodezhi-problemy-i-tendentsii (accessed: 09/28/2019).

9. Arshinova E.V., Bilan M.A., Gorbatova M.M., Rassokhina I.Yu. VALUE ASPECTS OF ELECTORAL BEHAVIOR OF STUDENT YOUTH / E.V. Arshinova, M.A. Bilan, M.M. Gorbatova, I.Yu. Rassokhina // Vocational education in Russia and abroad. 2019.No 1 (33). URL: https://cyberleninka.ru/article/n/tsennostnye-aspekty-elektoralnogo-pove deniya-studencheskoy-molodezhi (accessed date: 09/28/2019).

10. Karpenko O.M. , Lamanov I.A. Youth in the modern political process in Russia, M. 2006. -C. 52-53. 